\title{
Deudas pendientes en materia de género en la Universidad Católica del Maule
}

\section{Pending debts in terms of gender in the Universidad Catolica de Maule (Catholic University of Maule)}

ISSN 2071-8748

E-ISSN 2218-3345

\section{(c) $\$ 0$}

Juan Cornejo-Espejo jcornejo@ucm.cl

Recibido: 26/07/18 Aprobado: 12/12/18

URI: http://hdl.handle.net/11298/887

DOI: http://dx.doi.org/10.5377/entorno.v0i66.6732

\section{Resumen}

El capítulo, escrito a modo de ensayo, tiene como propósito reflexionar críticamente acerca de los avances, nudos críticos y resistencias culturales e institucionales que ha experimentado la UCM en los últimos años en materia de equidad e igualdad género. Con el propósito de visualizar esas tensiones se ha privilegiado el análisis de la documentación oficial a fin de identificar la presencia de lenguaje no sexista e inclusivo, además de conocer las políticas e iniciativas de género desarrollados por la institución en la última década, ya sea a través de orientaciones, estrategias y reivindicaciones académicas, o ya sea, a través de programas específicos de formación. La conclusión a la que se llega es que la UCM no sólo no evidencia un lenguaje no sexista e inclusivo en su documentación oficial, sino que muchas de las prácticas de sus autoridades podrían ser calificadas de autoritarias y arbitrarias, pese a que un número creciente de mujeres ha ocupado cargos directivos en los últimos años. Ellas más bien, parecieran reproducir y perpetuar dichas prácticas. Asimismo, se constatan resistencias institucionales al desarrollo de investigaciones cuyo eje central de reflexión

\section{Abstract}

The chapter, written as an essay, has as its purpose the critical reflection on the advances, critical issues, and cultural and institutional resistance that has experienced Universidad Catolica del Maule (UCM) in the last years regarding equity and gender equality. With the purpose of visualizing the strains, it has been privileged the analysis of official documents with the aim of identifying the presence of non-sexist and inclusive language; moreover, it provides information on the policies and the proposals of gender developed by the organization in the last decade, through guidance, strategies, and academic claims or with specific training programs. The conclusion that is reached is that the UCM not only does not show a non-sexist and inclusive language in its official documents but also many practices of its authorities could be tagged as authoritarian and arbitrary, even though an increasing number of women has held management positions in the last years. They, more like, appeared to reproduce and perpetuate the aforementioned practices. Furthermore, it has been found institutional resistance to the development of researches which central purpose 
son los estudios de género, desaprovechando con ello las posibilidades que le ofrecen las enseñanzas doctrinales para introducir mayores dosis de respeto y tolerancia. Todo lo anterior permite afirmar que aún son muchas las deudas en materia de género e inclusión que la UCM deberá intentar saldar a la brevedad, si realmente quiere ser fiel a su propia vocación de universidad católica.

\section{Palabras clave}

Universidades católicas; Estereotipo (psicología); Sociología de la educación; Desigualdad social. of reflection is the study of gender, wasting with it the possibilities that offer doctrinal teachings to add higher doses of respect and tolerance.

The information previously stated allows asserting that there are still many debts in terms of gender and inclusion that the UCM must try to solve, as soon as possible, if it genuinely pretends to be loyal to its vocation as a Catholic university.

\section{Keywords}

Catholic universities, Stereotype (psychology), Sociology of Education, Social Inequality.

\section{Introducción}

El presente capítulo, escrito más bien como un ensayo en torno a las deudas pendientes en materia de equidad e igualdad de género en la Universidad Católica del Maule Chile (UCM), tiene como propósito reflexionar críticamente acerca de los avances, nudos críticos y resistencias culturales e institucionales que ha experimentado la institución en los últimos años en relación con el tema.

Con el propósito de visualizar esas tensiones, se ha privilegiado, por una parte, el análisis de la documentación oficial a fin de identificar la presencia de lenguaje no sexista e inclusivo de acuerdo con la definición que proporciona el Ministerio de Educación (Mineduc, 2017) mediante su Unidad de Equidad de Género, la cual asigna una importancia crucial al lenguaje en tanto construcción de la realidad, pues, a su entender, la desigualdad se manifiesta también en el uso del lenguaje, que a lo largo de la historia ha omitido a la mitad de la población, perpetuando así la invisibilización de las mujeres, de los disidentes sexuales y de género, y de otros actores sociales.

Por otra parte, el análisis buscó conocer las políticas e iniciativas de género desarrolladas por la institución en la última década, ya sea mediante políticas, reivindicaciones académicas y laborales orientadas a garantizar la equidad e igualdad de género entre todos/as los miembros de la comunidad universitaria, o ya sea mediante la implementación de programas específicos de formación y estrategias de convivencia universitaria.

En el esfuerzo interpretativo, no se puede desconocer el hecho que la UCM es una institución confesional, esto es, una universidad católica de derecho diocesano dependiente del Obispado de Talca, cuyo Gran Canciller y, consecuentemente, máxima autoridad es el obispo local. Esta singularidad le imprime a la institución un sello particular que en algunos aspectos facilita ciertos procesos inclusivos coherentes y en sintonía con los valores evangélicos que promueve la Iglesia, pero en otros dificulta el seguimiento y respuesta oportuna a los requerimientos societales que demandan mayores dosis de equidad, igualdad y participación social.

En concreto, como es sabido, la Iglesia evidencia algunas dificultades y restricciones para una participación activa y plena de las mujeres, tanto en lo que respecta al acceso al ministerio sacerdotal, cuanto al ejercicio del poder y toma de decisiones al interior de la institución eclesiástica. Igual cosa ocurre con la aceptación de los/as disidentes sexuales y de género, que, pese a los discursos de corte paternalista de algunos sectores religiosos más progresistas, aún resienten el rechazo y condena de que son víctimas. Con todo, no se puede desconocer su afán por colocar en el centro de sus reflexiones y preocupaciones a la persona humana en tanto reflejo y expresión de la voluntad divina. 
En este sentido, son numerosos los documentos que subrayan esa centralidad y el deseo de la Iglesia de entrar en diálogo con el "mundo" y hacerse parte de las preocupaciones humanas. Síntesis e inspiración de esa vocación dialogal los Documentos del Concilio Vaticano II, que desde el punto de vista eclesial no solo se fundamentan en el "modelo pueblo de Dios", sino que insisten en la invitación a creyentes y no creyentes a colaborar en la construcción del Reino de Dios, que en lenguaje contemporáneo podría ser definido como un proyecto esencialmente humanizador e inclusivo, respetuoso de la condición humana. En el ámbito universitario, destaca la encíclica de Juan Pablo II (1991) Ex Corde Ecclesiae, en la cual no solo se subraya la búsqueda de la verdad, sino también el necesario diálogo entre fe y razón.

La UCM, en cuanto universidad, es una comunidad académica que, de modo riguroso y crítico, contribuye a la tutela y el desarrollo de la dignidad humana y de la herencia cultural mediante la investigación, la enseñanza y los diversos servicios ofrecidos a las comunidades locales, nacionales e internacionales. Ella goza de aquella autonomía institucional que es necesaria para cumplir sus funciones eficazmente y garantiza a sus miembros la libertad académica, salvaguardando los derechos de la persona y de la comunidad dentro de las exigencias de la verdad y del bien común Ex Corde Ecclesiae, n. ${ }^{112) .}$

En ese contexto se ha de entender el accionar de la UCM en el tema que nos convoca, pues, al ser una institución de Iglesia permanentemente, alude a la documentación eclesiástica en tanto fuente de inspiración y orientadora para la acción. Y si bien, como hemos subrayado más arriba, la Iglesia evidencia algunas restricciones en materia de género, por su vocación humanista da espacios al diálogo, a la vez que posibilita una relectura de esos mismos documentos a la luz de las nuevas realidades del mundo contemporáneo donde el género, en tanto expresión de la condición y riqueza humana, requiere ser resignificado y vivenciado al interior de la propia institución religiosa si se quiere ser fiel a esa misma vocación. Dicho en otros términos, el ensayo intenta dilucidar si la UCM, siguiendo las orientaciones doctrinales de la propia Iglesia, aprovecha los espacios de apertura y acercamiento a las nuevas realidades a que nos confrontan las reivindicaciones de equidad e igualdad de género; o por el contrario, en una fidelidad mal entendida que raya en el fundamentalismo cierra toda posibilidad al diálogo y al intento de establecer puentes de favorezcan el encuentro entre ideas y posturas que a primera vista pudieran aparecer como irreconciliables, limitándose apenas a un cumplimiento prescriptivo y desprovisto de toda convicción de las imposiciones legales que provienen del Estado que intentan asegurar un trato equitativo y justo entre los géneros.

Para dar respuesta a esta disyuntiva, el ensayo se subdivide en cuatro grandes ejes temáticos de reflexión. El primero de ellos, un análisis sumario de la documentación oficial de la universidad, más de los reglamentos de los centros de alumnos y sindicatos de académicos y funcionarios. Un segundo eje que busca delinear el ejercicio formal del poder expresado en cargos de gestión y dirección universitaria. Un tercer eje donde destacan las paradojas que devienen de prácticas que pueden ser definidas como excluyentes o de "inclusión perversa" de acuerdo con la terminología desarrollada por B. Sawaia (2002). Y un cuarto eje que describe una serie de amenazas institucionales y del entorno inmediato que, además de tornar poco creíble el discurso inclusivo de las autoridades universitarias, comprometen seriamente la autonomía, la libertad de expresión y el desarrollo de proyectos y programas efectivamente inclusivos, particularmente en materia de género. Finalmente, en las conclusiones, teniendo a la vista los antecedentes presentados, se evalúa críticamente el accionar de la universidad, subrayándose los avances logrados, pero también las deudas aún pendientes.

\section{Metodología}

Aun cuando el presente capítulo puede ser definido como un ensayo, y, por tanto, no pretende llegar a conclusiones definitivas producto de una investigación rigurosa apegada a cada una de las etapas que comprende una pesquisa científica, no se puede desconocer que su inspiración interpretativa deviene tanto del análisis de la documentación oficial de la propia universidad y de las enseñanzas doctrinales de la Iglesia contenidas en documentos conciliares, encíclicas y de la Conferencia Episcopal Latinoamericana, cuanto de la lectura de ciertos episodios acaecidos en la institución, así como del accionar de las autoridades universitarias. Vale decir, es a partir de un análisis documental y de ciertos episodios que se recurre a una interpretación libre que busca develar los avances, nudos críticos y resistencias culturales e institucionales experimentados por la UCM en la última década en materia de género. 
Considerando esos antecedentes, se podría decir que el ensayo, siguiendo una lógica metodológica, se inscribe en un paradigma interpretativo, con un enfoque eminentemente cualitativo, privilegiando el estudio de caso como diseño de investigación, constituyendo las unidades de análisis: 1) la presencia de lenguaje no sexista e inclusivo, 2) las políticas e iniciativas en perspectiva de género implementadas por la institución y 3) el accionar de las autoridades de la universidad.

Desde el punto de vista del análisis de la documentación oficial de la universidad, se recurre al análisis de contenidos cualitativo, el cual es definido "como una aproximación empírica, de análisis metodológicamente controlado de textos al interior de sus contextos de comunicación, siguiendo reglas analíticas de contenido y modelos paso a paso, sin cuantificación de por medio" (Mayring, 2000, p. 4).

El corpus documental analizado lo conformó la documentación oficial y de organizaciones de académicos/ as y funcionarios/as. El listado de documentos analizados es el siguiente:

- Proyecto Educativo Institucional (PEI) / Modelo Formativo / Plan Estratégico 2014-2018 / Informe de Autoevaluación Institucional

- Reglamento Académico / Reglamento de los Estudiantes

- Trabajo Académico / Trabajo Académico de Postgrado / Áreas Prioritarias de Investigación / Procedimiento de postulación, selección, seguimiento y cierre de un perfeccionamiento académico

- Pari-UCM (Orientaciones generales de trabajo con estudiantes con discapacidad que presenten necesidades educativas) / Protocolo de actuación ante conducta de acoso sexual dentro de la comunidad universitaria de la Universidad Católica del Maule

- Estatutos del Sindicato de Académicos / Estatutos del Sindicato de Funcionarios y Administrativos / Contrato Colectivo de los Académicos / Estatuto de funcionamiento de los centros de alumnos

\section{Análisis de la documentación oficial de la UCM}

Del análisis documental se desprende que, salvo alusiones genéricas, inspiradas en algunos documentos de la Iglesia que hablan de la persona humana como, por ejemplo, en la visión y misión institucionales, la documentación en términos generales carece de un lenguaje inclusivo, caracterizándose más bien por un lenguaje sexista, pues continúa asociando al hombre con la humanidad; o habla de los estudiantes, los académicos...

\section{Misión}

"La Universidad Católica del Maule se proyecta como una comunidad universitaria con una identidad fundada en los valores cristianos, capaz de liderar procesos de cambio y reflejar en su quehacer excelencia y calidad. Aspira a ser una institución que forme personas íntegras con vocación de servicio, protagonistas e impulsoras de cambio y desarrollo en la región, el país y el mundo (...)" (UCM, 2014a, p. 19.)

\section{Visión}

"La Universidad Católica del Maule contribuye a la misión evangelizadora de la Iglesia y asume los desafíos de la Región del Maule y de Chile mediante el cultivo del pensamiento, las ciencias, las artes y la cultura desde la perspectiva cristiana. Busca la formación de profesionales integrales, con una visión crítica, constructiva y una orientación cristiana del mundo, que asume los desafíos del entorno, entregando soluciones que guían el desarrollo de las comunidades y organizaciones en las que se insertan y respetando el medio ambiente (...)" (UCM, 2014a, p. 19.)

Es importante consignar que esa forma de escribir no es exclusiva de la UCM, sino de muchos de los documentos de la propia Iglesia, que alternan una noción más androcéntrica, especialmente la más antigua, con una noción más holística e inclusiva, mucho más visible en la documentación más reciente. Ello, probablemente, motivado por los cuestionamientos y presiones sociales que demandan por la incorporación de un lenguaje no sexista y mucho más inclusivo. Ejemplo de lo anterior, es un extracto del modelo formativo donde se alternan las dos formas de escribir: "A través de un sello humanizador, el proceso de formación profesional que caracteriza el modelo educativo de la UCM busca contribuir al desarrollo integral del estudiante, de tal manera que sus egresados sean un aporte al desarrollo de una sociedad más justa que dignifique al ser humano y su cultura (...)" (UCM, 2014b, p. 12).

En resumen, se puede afirmar que es en las grandes definiciones y en la declaración de principios donde se verifica con mayor claridad un lenguaje más inclusivo y con una vocación más universalista. En el resto de los textos, 
particularmente aquellos de orden administrativo, tiende a predominar un lenguaje marcadamente sexista (Mineduc, 2017), donde no se distinguen géneros y, simplemente, se habla de los estudiantes, los académicos, los candidatos, los egresados, los directores, los vicerrectores, etc.

Sin embargo, desde el punto de vista de la inclusión y las demandas feministas, destacan dos documentos de reciente creación. Las "Orientaciones generales de trabajo con estudiantes con discapacidad que presenten necesidades educativas" (Pari-UCM) y el "Protocolo de actuación ante conducta de acoso sexual dentro de la comunidad universitaria de la UCM". El primero proporciona algunas orientaciones a los/as académicos/as para la atención de los/as estudiantes con discapacidad física o capacidades físicas diferentes. Apelando al texto de la Ley 20.422 (2010), se señala que la universidad "busca asegurar el derecho a la igualdad de oportunidades de las personas con discapacidad, con el fin de obtener su plena inclusión, asegurando el disfrute de sus derechos y elimando cualquier forma de discriminación fundada en la discapacidad" (p. 4).

Básicamente, el documento orienta acerca de las adaptaciones curriculares que es necesario introducir en estos casos, así como para la docencia y evaluación de estos/as estudiantes. $\mathrm{Y}$ aun cuando el documento representa un gran avance, pues visibiliza una realidad cada vez más presente en las aulas, poco dice de las adaptaciones de infraestructura que son necesarias para una atención adecuada. La UCM, pese a los esfuerzos que ha hecho en este sentido, aún tiene muchas deudas pendientes, tanto desde el punto de vista de los accesos (mejoramiento de rampas, instalación de elevadores en edificios de más de un piso, etc.) como del de equipamiento representado, por ejemplo, en software especializados que faciliten el acceso a la información de los/as estudiantes que presentan algún grado de discapacidad visual o auditiva.

Nada se dice tampoco de los/as estudiantes que presentan algunos problemas de aprendizaje 0 trastornos de personalidad, que, en virtud de la expansión del sistema universitario chileno, explicable en gran medida por la ampliación de la gratuidad y la multiplicación de vías alternativas de ingreso a la educación superior, además de las pruebas de selección, su presencia se ha hecho más notoria en los últimos 2 o 3 años.
En lo respecta a las demandas feministas, que han derivado en ocupaciones de numerosas universidades a lo largo de todo el país durante el primer semestre de 2017, uno de sus ejes centrales de reivindicaciones está referido a la prevención, manejo y sanción del acoso sexual, especialmente hacia las mujeres en entornos educativos. En el caso de la UCM, resulta llamativo y positivo a la vez que de alguna forma se haya anticipado al petitorio feminista. Durante el año recién pasado, la Dirección General Estudiantil, con la participación de algunos estudiantes, elaboró un protocolo de acción ante eventuales situaciones de acoso sexual que pudieran darse al interior de la UCM.

El aspecto positivo es que se anticipó a la formalización del petitorio a escala nacional. No obstante, debe reprochársele no solo la baja participación estudiantil, sino la nula participación de académicos/as y funcionarios/as de la universidad en su diseño y elaboración, lo cual ha redundado en desconocimiento de la existencia del citado documento. Sin contar, además, con que un documento de esa naturaleza, para ser realmente efectivo, debe haber sido discutido y elaborado con la participación de todos los estamentos de la universidad y no apenas por una unidad administrativa.

Esta dinámica de actuación torna sospechosa cualquier iniciativa en este sentido, pues da la impresión que, dadas las nuevas exigencias de los procesos de acreditación universitaria, que exigen una serie documentos y protocolos, además de los estrictamente curriculares, financieros y administrativos como era la tónica tradicional, se está más interesado en satisfacer los nuevos requerimientos de acreditación que en cimentar y consolidar prácticas inclusivas expresadas en el desarrollo de políticas y orientaciones que aseguren la efectividad y continuidad de esas prácticas, el compromiso con el cambio mediante la formulación de objetivos transversales para todas las carreras y en todos los niveles, además de la innovación curricular.

En otras palabras, considerando la falta de debate y reflexión, junto con la escasa o nula participación de la comunidad universitaria en el diseño y elaboración de estos documentos y protocolos, se tiende a creer que su repentina y sorpresiva irrupción responde más bien a las lógicas y exigencias de los procesos de acreditación universitaria que a un deseo sincero de tornar más inclusiva la vida universitaria. A este respecto, cabe recordar que en 
las visitas de pares evaluadores se verifica la existencia de determinados documentos, protocolos e indicadores por medio de un check list, pero sin verificar en terreno si esos documentos responden a programas en marcha, haciéndose un voto de fe en lo que declaran las instituciones sometidas a acreditación.

Otro grupo de documentos analizados, no directamente vinculados con la administración de la universidad, sino más bien con las relaciones contractuales entre los/ as académicos/as y funcionarios/as con la institución, o la estructura organizativa de los centros de alumnos/as son: los estatutos del Sindicato de Académicos/as y de Funcionarios/as y Administrativos/as, más el respectivo contrato colectivo de los/as académicos/as y el estatuto de funcionamiento de los centros de alumnos/as.

Estos documentos, al igual que como ocurre con la documentación oficial de la UCM, están redactados en lenguaje sexista y no inclusivo. Situación, probablemente, explicable en el caso de los estatutos sindicales por la época en que fueron escritos (hace ya más de dos décadas), sin haber sufrido alteraciones significativas pese al paso del tiempo. En el caso del estatuto de funcionamiento de los centros de alumnos/as, la explicación es similar a la de la documentación oficial; esto es, no ha habido interés o voluntad por actualizar el lenguaje y sintonizarlo con las nuevas demandas sociales de equidad e igualdad de género.

Con todo, lo más llamativo de este grupo de documentos, más allá de la desactualización desde el punto de vista del lenguaje, es que en ninguno de ellos hay alusión directa a cuestiones de género, y menos aún a reivindicaciones feministas. Situación que, a lo menos, resulta curiosa porque en el caso de los sindicatos desde su creación han hecho parte de sus directivas mujeres. Es más, en la presente década dos mujeres han presidido el sindicato de académicos/as por más de un período. Básicamente todas las reivindicaciones presentes en el contrato colectivo aluden a mejoras laborales generales, sin distinciones de género o demandas de políticas de discriminación positiva hacia las mujeres, por ejemplo, motivadas por las complejidades que supone la maternidad.
En lo que respecta a los estatutos de los centros de alumnos, la situación no es muy distinta. Todo está redactado en términos generales sin distinción de género. $Y$ al igual que en los sindicatos de académicos/as y funcionarios/ as, no obstante mujeres integrar las respectivas directivas y aún haber ocupado la presidencia de la Federación de Estudiantes, no ha habido reivindicaciones específicas. El punto de inflexión, en el caso de los/as estudiantes, está representado por las movilizaciones feministas que están teniendo lugar en las universidades más importantes del país. En este sentido, los/as estudiantes de la UCM, y particularmente las estudiantes, han tenido una actitud más bien expectante respecto de lo que ocurría en otras universidades, sumándose muy recientemente al citado movimiento.

\section{Evolución en la distribución de cargos de gestión y} dirección en la UCM

Un segundo aspecto que requiere ser analizado a la luz de las demandas feministas de equidad e igualdad de género en el ámbito universitario es la referida a la distribución de cargos de gestión y dirección. Tradicionalmente las instituciones de educación superior, amparadas en el principio de igualdad de oportunidades, no han desarrollado políticas específicas que garanticen un acceso equitativo de todos/as los/as académicos a los cargos directivos. Muy recientemente algunas universidades del país han introducido ciertas medidas tendientes a asegurar una participación más activa de las mujeres.

A este respecto cabe señalar, como se aprecia en las siguientes tablas, que los cargos directivos en la UCM eran ocupados, a inicios de la presente década, mayoritariamente por hombres. Es más, en épocas pasadas, inclusive, muy excepcionalmente una mujer ocupó algún cargo directivo. Las pocas mujeres que lo hicieron se concentraron en las facultades de Educación y Salud y, básicamente, en direcciones de escuelas. Tendencia que de algún modo ratifica las limitaciones que afectan a las mujeres académicas representadas en la noción "techo de cristal", y en la concentración en ciertas facultades o áreas del conocimiento (Cornejo y Belmar, 2016). 
Tabla 1: Distribución de cargos de acuerdo con sexo (frecuencia)

\begin{tabular}{|l|l|l|l|l|l|l|l|l|l|l|l|l|l|}
\hline & $\mathbf{2 0 0 6}$ & $\mathbf{2 0 0 7}$ & $\mathbf{2 0 0 8}$ & $\mathbf{2 0 0 9}$ & $\mathbf{2 0 1 0}$ & $\mathbf{2 0 1 1}$ & $\mathbf{2 0 1 2}$ & $\mathbf{2 0 1 3}$ & $\mathbf{2 0 1 4}$ & $\mathbf{2 0 1 5}$ & $\mathbf{2 0 1 6}$ & $\mathbf{2 0 1 7}$ & $\mathbf{2 0 1 8}$ \\
\hline M & 20 & 25 & 24 & 25 & 31 & 33 & 37 & 39 & 43 & 49 & 54 & 59 & 58 \\
\hline H & 46 & 44 & 43 & 50 & 49 & 56 & 59 & 62 & 56 & 51 & 49 & 50 & 52 \\
\hline
\end{tabular}

Fuente: creación propia con base en datos proporcionados por la Dirección de Recursos Humanos de la UCM.

Tabla 2: Distribución de cargos de acuerdo con sexo (porcentaje)

\begin{tabular}{|l|l|l|l|l|l|l|l|l|l|l|l|l|l|}
\hline & $\mathbf{2 0 0 6}$ & $\mathbf{2 0 0 7}$ & $\mathbf{2 0 0 8}$ & $\mathbf{2 0 0 9}$ & $\mathbf{2 0 1 0}$ & $\mathbf{2 0 1 1}$ & $\mathbf{2 0 1 2}$ & $\mathbf{2 0 1 3}$ & $\mathbf{2 0 1 4}$ & $\mathbf{2 0 1 5}$ & $\mathbf{2 0 1 6}$ & $\mathbf{2 0 1 7}$ & $\mathbf{2 0 1 8}$ \\
\hline $\mathbf{M}$ & 30,3 & 36,2 & 35,8 & 33,3 & 38,7 & $\mathbf{3 7}$ & 38,5 & 38,6 & 43,4 & 49 & 52,4 & 54,1 & 52,7 \\
\hline $\mathbf{H}$ & 69,9 & 63,7 & 64,1 & 66,6 & 61,2 & 62,9 & 61,4 & 61,3 & 56,5 & 51 & 47,5 & 45,8 & 47,2 \\
\hline
\end{tabular}

Fuente: creación propia con base en datos proporcionados por la Dirección de Recursos Humanos de la UCM.

Y si bien, como se aprecia en las tablas, ha habido un aumento significativo y constante en la participación de las mujeres en la dirección universitaria desde el año 2014 a la fecha, coincidente con la actual rectoría, no se puede obviar el hecho de que tal situación no es producto de una política de género implementada por la universidad, sino de la voluntad del actual rector. Todavía más, la institución, salvo el protocolo de prevención del acoso sexual, carece de una política específica de género que atienda los intereses, las problemáticas y expectativas tanto de las mujeres académicas y funcionarias como de las estudiantes.

De este modo, la creciente participación de las mujeres en la dirección universitaria perfectamente podría revertirse en esta o en una futura rectoría, pues no hay nada que la asegure al estar sujeta al arbitrio de las autoridades de turno. Cuestión que no resulta del todo descabellada, considerando que el rector y los consejeros externos ${ }^{1}$ son designados por el obispo local, el cual a su vez designa a todas las otras autoridades de la universidad. ${ }^{2}$ Esta característica, sin duda, representa una seria limitación y amenaza en las universidades católicas que, en su mayoría, carecen de mecanismos democráticos para la elección de las autoridades $\mathrm{y}$, consecuentemente, de representatividad de estas. No siempre los cargos de dirección son ocupados por los/as más idóneos o capacitados, pues, por sobre la meritocracia, a veces prevalecen otros criterios, como la adhesión religiosa, u otros que poco tienen que ver con lo estrictamente académico, como la exclusión de los/as divorciados/as o de los/as disidentes sexuales.

Y aun cuando estos criterios no son exclusivos de las instituciones católicas (varios de ellos son aún extremos 0 radicales en otras instituciones pertenecientes a otras denominaciones religiosas o filosóficas), sin lugar a dudas, representan un serio obstáculo en los procesos democratizadores y participativos de las instituciones de educación superior; además de dar pocas garantías de resguardo de los derechos de todos/as los/as miembros de las comunidades universitarias, especialmente cuando se trata de equidad e igualdad de género, tema que tradicionalmente ha sido invisibilizado y silenciado aún en las instituciones más pluralistas.

Por otro lado, en un intento por evaluar críticamente la participación de las mujeres en los cargos de dirección de la UCM, como se señaló en un estudio realizado por J. Cornejo y M. Belmar (2018) en la misma institución, se concluyó

1 El Consejo Superior, además de estar encabezado por el obispo local en calidad de Gran Canciller, está integrado por el rector (que normalmente preside dicho Consejo), por los/as vicerrectores/as, los/as decanos/as (en calidad de consejeros internos) y cinco consejeros externos.

2 La excepción la constituyen los decanos, quienes son elegidos por el cuerpo de académicos/as de las respectivas facultades. No obstante, dicha elección no es garantía de que se va a ocupar el cargo, pues requiere de la ratificación del obispo local. 
que el aumento en el número de mujeres que ocupaban cargos directivos en la actual Rectoría no había supuesto un cambio significativo no solo en el desarrollo de políticas de género, sino que las relaciones entre las autoridades y el resto de la comunidad universitaria habían empeorado. Tan es así que nunca en la historia de la universidad había habido tantas acusaciones de acoso laboral consignadas en los tribunales del trabajo como en los últimos años. Varias de ellas atribuidas directamente a mujeres que ocupaban cargos de dirección.

Vale decir, arbitrariedades y autoritarismo, tan propios de un régimen patriarcal, parecieran haberse perpetuado en la actual administración, situación que nos induce a pensar que no basta con la presencia de mujeres en cargos directivos o leyes de cuotas. Estas últimas, si bien representan un avance, son insuficientes. Un verdadero cambio que no aspire al término del paradigma patriarcalmachista, con todos sus mandatos de sexismo, homofobia o autoritarismo, es simplemente un cambio estético. Una auténtica revolución de género supone necesariamente una nueva forma de ejercer el poder y relacionarse entre los géneros $y$, consecuentemente, entre todos/as los/as miembros de una comunidad.

Paradojas que traban o entorpecen las aspiraciones de equidad e igualdad de género en la UCM

Algunas paradojas que resultan preocupantes no solo porque entorpecen las aspiraciones de equidad e igualdad de género, sino también porque limitan las posibilidades de investigación, producción académica y desarrollo intelectual son algunas restricciones para el tratamiento de algunos temas considerados tabús o que son vistos con recelo y desconfianza. Entre estos destacan temáticas referidas a sexualidad y al VIH/Sida, pero sobre todo algunos aspectos teóricos de los estudios de género, la teoría queer y todo aquello que cuestione el binarismo sexual. En relación con los primeros, a modo de ilustración de las restricciones veladas que operan sobre algunos temas, tenemos, por ejemplo, el despido acaecido durante el 2016 de la vicerrectora de Administración y Finanzas, entre otros motivos, por haber apoyado una publicación de una organización de personas viviendo con $\mathrm{VIH} /$ Sida.

En relación con los cuestionamientos teóricos, podemos citar la negativa de las autoridades de la Vicerrectoría de Investigación y Postgrado de aprobar un proyecto que daba vida a un programa de doctorado en inclusión educativa, que entre otras líneas de investigación (trastornos del aprendizaje, interculturalidad, migraciones, etc.) proponía una de género, con el propósito de problematizar el tema en el ámbito escolar. A este respecto, es importante consignar que el proyecto no sufrió cuestionamiento alguno cuando fue sometido al parecer del Consejo Académico, salvo algunas observaciones referidas a la citación de algunas autoras, tales como Judith Butler, o que se hablase de la diversidad sexual en circunstancias que la Iglesia, como señaló el director de Postgrado de la época (2017) en entrevista con los creadores del programa, solo acepta la idea de sexo binario; es decir, macho y hembra con la correspondiente expresión de género, obviando o rechazando cualquier otra expresión de género. $Y$ aun cuando se omitió en una reformulación del proyecto, a solicitud de ese mismo director mandatado por autoridades superiores, cualquier referencia teórica a autores o corrientes que pudieran resultar controversiales a la luz de las enseñanzas de la Iglesia, este nunca fue sometido a revisión. Es más, hasta la fecha (dos años desde la presentación original) no ha habido un pronunciamiento oficial.

Situación muy parecida es lo ocurrido a propósito de la presentación de un proyecto para la creación de un centro de estudios de género y sexualidad. En este caso, el proyecto ni siquiera fue sometido a evaluación, aun cuando, por lo que establecían las propias bases del concurso, en vista de dar mayor objetividad y transparencia al proceso, los proyectos serían enviados a evaluadores externos (sistema de doble ciego). Pese a que se va a enterar un año de la fecha límite en que debieron ser informados los resultados a los investigadores proponentes, ni los resultados del concurso ni mucho menos la evaluación externa ha sido entregada. En otras palabras, se ha convertido en una práctica recurrente, de parte de las autoridades de la UCM, no dar respuesta o prestar apoyo a proyectos, programas, propuestas de investigación u otros que supongan estudios o iniciativas de género. El silenciamiento e invisibilización tanto de la temática como de los/as cultores de estas disciplinas se han convertido en una política oficial no explícita.

Semejante actitud, que en principio pudiese ser interpretada como de indiferencia frente al tema, la verdad no es tal, pues el ignorar las solicitudes y demandas no es una actitud casual sino premeditada, que busca eludir cualquier acusación o responsabilidad que se pudiera encuadrar dentro de la Ley (20.609/2012) Antidiscriminación. De 
ese modo, al no prohibir expresamente un estudio o una iniciativa de género, sino simplemente desconocerla, no se puede apelar discriminación; a lo sumo, desinterés.

En virtud de estos antecedentes, se puede afirmar, entonces, que hay de parte de las autoridades un marcado pragmatismo y cinismo que se corresponde con las dudas que manifestábamos acerca de su convicción acerca de la necesidad de una educación auténticamente inclusiva, expresados en los protocolos de acoso sexual y de acogida de los/as estudiantes con discapacidad física. Lo cierto parece ser, como señalamos en esa oportunidad, que, además de una "inclusión perversa", lo que subyace de fondo es simplemente el deseo de cumplir con los requisitos formales de los procesos de acreditación universitaria, pero de ningún modo la voluntad de un cambio estructural que suponga la deconstrucción del patriarcado y, consecuentemente, de la forma de administrar y ejercer el poder.

Para los/as estudiantes que pretenden desarrollar temáticas de este tipo en sus tesis de grado, especialmente cuando aluden a las disidencias sexuales y de género, pesa la misma censura. Mediante prohibiciones y censuras veladas, se busca desincentivar su estudio. Así, no es extraño que una directora de un programa de Magíster en Orientación Educacional y Vocacional, por ejemplo, ante el interés manifestado por algunos/as estudiantes de desarrollar pesquisas en torno a los problemas y desafíos que supone la presencia de estudiantes Lesbianas, Gays, Bisexuales, Trans e Intersexuales (LGBTI) para la escuela, simplemente los/as desanime diciéndoles que esas temáticas no están dentro de las líneas de investigación del programa. Lo curioso es que, precisamente, la línea de investigación declarada por ese mismo programa es "inclusión educativa", entendida esta desde una perspectiva amplia y no limitada a las necesidades educativas especiales.

\section{Amenazas institucionales y del entorno inmediato}

Una primera amenaza que se cierne sobre la mayor parte de las universidades católicas es la ausencia de un sistema democrático de elección de sus autoridades, situación que se ve agravada en múltiples oportunidades por un ejercicio del poder autoritario y arbitrario, particularmente cuando es ejercido por religiosos o laicos que se adhieren a posturas conservadoras en materia moral o entienden el derecho canónico como un cuerpo legal que se superpone 0 antecede al mensaje evangélico. Para los adherentes a estas posturas, la voluntad de Dios está representada por una obediencia ciega a las autoridades eclesiásticas o a sus delegados, y donde cualquier disidencia o desacuerdo es interpretado como una traición o una grave falta que atenta contra el querer de Dios. En ese sentido, estas personas confunden la Iglesia, en tanto realidad suprahumana, y aún a Dios mismo, con sus intereses, percepciones o caprichos. Iluminadoras resultan desde esta perspectiva las palabras del teólogo dominico brasileño Frei Betto, quien aludiendo a estos grupos en la Iglesia señala:

El fariseo, por el contrario, se deja petrificar en el pasado. Incapaz de autocrítica y sordo a las críticas, se juzga dueño de la verdad. Investido de prepotencia, cabalga sobre arrogancias. Es esa resistencia conservadora y farisaica la que suscita tanta oposición al papa Francisco, dentro y fuera de la Iglesia Católica. Sus detractores fingen estar convencidos de que Jesús excluyó a las mujeres del sacerdocio, instituyó la misa en latín, condenó al infierno a los homosexuales y recomendó a los pobres vivir resignados con su carencia de bienes y conformes con la opulencia de los ricos (...). Ya no hay lugar para una Iglesia triunfalista, apegada al poder, homofóbica e indiferente a los temas socio ambientales y a la causa de la justicia. El dios de los fariseos no se asemeja en nada al Dios de Jesús (Frei Betto, 2018, p. 3).

En el caso de la Universidad Católica del Maule, además de ausencia de un sistema democrático y participativo, se evidencia falta de transparencia en su manejo de la universidad. Falta que se manifiesta no solo en el desconocimiento de los criterios de selección de sus autoridades, sino también en el manejo de sus finanzas, del diseño y puesta en marcha de sus políticas institucionales y de sus planes y proyecciones futuras. Básicamente se trata de una universidad que se piensa de espalda a su comunidad universitaria. $Y$ si bien estas no son condiciones que compartan todas las universidades católicas del país, sus contradicciones se tornan más evidentes por tratarse de una universidad pequeña cuya matrícula no sobrepasa los 8.000 estudiantes. Condición que se esperaría fuese un aliciente para sus miembros, para sentirse parte de una institución próxima y participativa.

En este contexto no resulta extraño que no existan políticas de equidad e igualdad de género, y que la elección de varias de las mujeres que ocupan cargos directivos, más 
que un reconocimiento a sus trayectorias académicas o su compromiso con causas feministas y derechos humanos, sea más bien fruto del voluntarismo personalista de las autoridades de turno que ven en estas mujeres a personas obsecuentes, acríticas y obedientes ejecutoras de sus instrucciones.

Esta forma de entender la universidad no solo devela una falta de sintonía con lo que ocurre a escala nacional en materia de género y educación, sino que deja al descubierto un catolicismo nominal, y, por qué no decirlo, "oportunista" de muchas de las autoridades de la UCM, que no se importan con adherir a discursos conservadores (aun cuando en su fuero interno no los compartan) que intentan desacreditar los estudios de género, acusándolos de contener los principios de la "ideología de género". Acusación que además de desinformada deja de manifiesto el cinismo y oportunismo de muchos y muchas que no se importan con atentar contra la libertad de pensamiento y de conciencia, tan propios y definitorios del quehacer universitario, con tal de obtener un cargo o mantenerse en él.

No menos amenazante y preocupante resultaba la presencia del obispo Horacio Valenzuela, Gran Canciller de la universidad, que había sido vinculado al "caso Karadima" en calidad de encubridor. ${ }^{3}$ Acusación que le terminó costando el cargo al ser destituido por el papa Francisco. Conocido era su conservadurismo y resistencias a los estudios de género. Es más, durante el aniversario de la institución, a fines de agosto de 2017, con la asistencia y apoyo de dos profesoras de la Universidad de Los Andes (institución vinculada con el Opus Dei) denunció como aberrantes los procesos de apoyo y contención de los niños/as trans.

\section{Discusión}

Más allá de la descripción de situaciones o prácticas que van en la línea contraria de la inclusión o del desarrollo de políticas de género, resulta pertinente preguntarse cómo la UCM aprovecha los espacios que la propia Iglesia institucional, contenidos en sus enseñanzas doctrinales o en sus vivencias pastorales, para introducir mayores dosis de respeto, tolerancia, creatividad, libertad... en su propio quehacer universitario.
Como es sabido, la Iglesia evidencia algunos problemas con el reconocimiento de la tercera o cuarta ola de derechos humanos, especialmente cuando ellos subrayan una participación equitativa e igualitaria de hombres y mujeres en todas las instancias e instituciones, o en el reconocimiento de las disidencias sexuales y de género que no se ajustan a los estrictos márgenes del paradigma heterosexista. Sin embargo, no se puede desconocer que ella ha sido, a partir de la segunda mitad del siglo XX, especialmente a partir de Vaticano II, una clara defensora de los sistemas políticos democráticos (particularmente en América Latina en momentos de crisis políticoinstitucional que derivaron en dictaduras cívico-militares) y de los derechos económico-sociales de las clases obreras y más desposeídas, contenidos en la Doctrina Social de la Iglesia.

Por lo pronto, la UCM, en sus definiciones conceptuales o declaración de principios, se adhiere a muchos de los postulados declarados por la institución eclesiástica, principalmente aquellos que recalcan la dignidad y el respeto de la persona humana. Así, en su Proyecto Educativo Institucional, siguiendo las enseñanzas de la Encíclica $E X$ Corde Ecclesiae (1991), afirma:

La Universidad Católica, en cuanto Universidad, es una comunidad académica, que, de modo riguroso y crítico, contribuye a la tutela y desarrollo de la dignidad humana y de la herencia cultural mediante la investigación, la enseñanza y los diversos servicios ofrecidos a las comunidades locales, nacionales e internacionales ( $E X$ Corde Ecclesiae, 12).

La Universidad Católica es, por consiguiente, el lugar donde los estudiosos examinan a fondo la realidad con los métodos propios de cada disciplina académica, contribuyendo así al enriquecimiento del saber humano (...). Tal investigación, además de ayudar a los hombres y mujeres en la búsqueda constante de la verdad (...). En una Universidad Católica la investigación abarca necesariamente: a) la consecución de una integración del saber; b) el diálogo entre fe y razón; c) una preocupación ética y d) una perspectiva teológica ( $E X$ Corde Ecclesiae, 15).

3 El "caso Karadima" se refiere a las denuncias de abuso en contra del sacerdote chileno Fernando Karadima, por parte de feligreses y de exsacerdotes de la parroquia El Bosque, presentadas desde 2004 a la autoridad eclesiástica. El caso involucró tanto a la Iglesia chilena como a la Santa Sede, y provocó dudas acerca del papel de la justicia civil en el país, debido a que el fallo de la Santa Sede, en el cual se declaraba culpable de abusos a Karadima, se emitió antes de que la justicia decidiera reabrir la investigación contra el citado sacerdote. 
Asimismo, recoge, por ejemplo, del Documento de Puebla (1979), el sentido que debe tener una educación humanizadora y evangélica:

La educación humaniza y personaliza al hombre cuando logra que éste desarrolle plenamente su pensamiento y su libertad, haciéndolos fructificar en hábitos de comprensión y de comunión con la totalidad del orden real, por los cuales el mismo hombre humaniza su mundo, produce cultura, transforma la sociedad y construye la historia (Puebla, n.o 1025).

La educación evangelizadora asume y completa la noción de educación liberadora porque debe contribuir a la conversión del hombre total, no sólo en su yo profundo e individual, sino también en su yo periférico y social, orientándolo radicalmente a la genuina liberación cristiana [...] (Puebla, n.o 1026)

No obstante, esas alusiones que evocan respeto y tolerancia no se corresponden con las políticas, creencias y prácticas (Both \& Ainscow, 2000) en materia de género e inclusión que promueve la UCM en su quehacer cotidiano y que subyacen en las actitudes de sus autoridades, pues no solo contradicen abiertamente esas mismas enseñanzas, sino que vulneran los derechos de personas y grupos disidentes. Y lo que es más preocupante, tratándose de una universidad, no aprovechan los márgenes de libertad y creatividad que admite la propia doctrina. Es decir, más allá de las declaraciones y adhesiones nominales, la UCM no cumple con el mandato básico propuesto por la propia Iglesia para las universidades católicas, cual es tender puentes entre la fe y la cultura, entre la fe y la razón. De otra forma, no se entiende la obcecación y rechazo a reflexionar acerca de las problemáticas con que nos deparan los estudios de género en las sociedades contemporáneas o de introducir reformas que verdaderamente tiendan a la inclusión de todos y todas los/as miembros de la comunidad universitaria sin exclusiones o restricciones de ningún tipo.

\section{Conclusiones}

A modo de conclusión, se puede decir que la UCM en lo inmediato debería promover un lenguaje no sexista e inclusivo en su documentación oficial. Ello, sin embargo, sería insuficiente si no fuese acompañado de políticas institucionales auténticamente inclusivas y en perspectiva de género, que contribuyeran al mejoramiento de las relaciones entre autoridades y comunidad universitaria, y al restablecimiento de las confianzas. Asimismo, este proceso de cambios y renovación debería ir acompañado de la democratización no solo de la elección de las autoridades, sino de los procesos de toma de decisiones de modo de tornarlos más participativos. En este sentido, un mayor protagonismo y participación de las mujeres en cargos de gestión y dirección universitaria no debería limitarse a la paridad de género, sino aspirar a un cambio en el modo de ejercer el poder, a fin de terminar con prácticas autoritarias y arbitrarias tan características de un régimen patriarcal-machista. Es decir, se debería tender a un cambio estructural, cuyo fin último sea la deconstrucción de dicho orden. No aspirar a aquello es simplemente quedarse en las formas y no apuntar al fondo. Es conformarse con una "inclusión perversa", que aparenta cambiarlo todo, pero en realidad no cambia nada. En suma, atender a estas deudas es ser coherentes y fieles al mensaje evangélico que debería inspirar y nortear el quehacer de esta institución.

\section{Referencias}

Booth, T. y Ainscow, M. (2000). Índice de inclusión: desarrollando el aprendizaje y la participación en las escuelas. Bristol: CSIE/Unesco - Orealc.

Conferencia General del Episcopado Latinoamericano (1979). "Documento de Puebla". Santiago: Ediciones Paulinas. Recuperado el 1 de julio de 2018 de http:// www.celam.org/doc_conferencias/Documento_ Conclusivo_Puebla.pdf

Concilio Vaticano II (1986). "Documentos del Concilio Vaticano I". Madrid: Biblioteca de Autores Cristianos.

Cornejo, J. y Belmar, M. (2017). “Equidad e igualdad de género en la óptica de los/as estudiantes de pedagogías de la Universidad Católica del Maule - Chile". Investigación en diseño y atención a las oportunidades de género en la educación superior. Cochabamba: Universidad Mayor de San Simón, pp. 85-101

Cornejo, J. y Belmar, M. (2018). "Mujeres en cargos directivos en la UCM: Evaluación de desempeño desde la perspectiva de los y las académicos y de las propias implicadas". Revista Ciencias Sociales, n.o 4, 107-123.

Frei Betto (2018, junio 5). "Fariseísmo conservador". Orbe, quincenario editado por Prensa Latina. San Salvador, p. 3

Hernández, R. (1994). Metodología de la investigación. México: McGraw-Hill.

Juan Pablo II (1990). "Constitución Apostólica EX Corde Ecclesiae Sobre las Universidades Católicas". 
Recuperado el 1 de julio de 2018 de http://w2.vatican. va/content/john-paul-ii/es/apost_constitutions/ documents/hf_jp-ii_apc_15081990_ex-cordeecclesiae.html

Mayring, P. (2000) "Qualitative content analysis". Forum qualitative social research, 1(2) Recuperado el 1 de julio de 2018: http://qualitativeresearch.net/fqs/fqse/2-00inhalt-e.htm

Ministerio de Educación de Chile (2017). "Orientaciones para un uso de lenguaje no sexista e inclusivo". Santiago: Mineduc. Recuperado el 15 de julio de 2018 de https://www.mineduc.cl/wp-content/uploads/ sites/19/2017/09/Manual-Lenguaje-Inclusivo-NoSexista.pdf
Sawaia, B. [Org.] (2002). As artimanhas da exclusão - analise psicosocial e ética da desigualdade social. Petrópolis: Vozes.

Universidad Católica del Maule - UCM (2014a). Proyecto educativo institucional. Talca: Ediciones UCM. Recuperado el 15 de julio de 2018 de file:///C:/Users/ cornejo/Desktop/Dctos\%20UCM\%20(Alicante\%20 2018)/Proyecto\%20Educativo\%20Institucional\%20 UCM.pdf

Universidad Católica del Maule - UCM (2014b). Modelo formativo. Talca: Ediciones UCM. Recuperado el 15 de julio de 2018 de file:///C:/Users/cornejo/Desktop/ Dctos\%20UCM\%20(Alicante\%202018)/Modelo\%20 Formativo\%20UCM.pdf 